\title{
Thermal and Dynamics Mechanical Analysis of Polypropylene Blown Films with Crude Palm Oil as Plasticizer
}

\author{
Siti Hasnah Kamarudin ${ }^{1,2}$, Emiliana Rose Jusoh ${ }^{1,3, *}$, Luqman Chuah Abdullah ${ }^{1,3,{ }^{* *}}$, Mohd Halim Shah \\ Ismail $^{3}$, Min Min Aung ${ }^{1,4}$, and Chantara Thevy Ratnam ${ }^{5}$ \\ ${ }^{1}$ Institute of Tropical Forestry and Forest Products, Universiti Putra Malaysia, 43400 Serdang, Selangor, Malaysia \\ ${ }^{2}$ School of Industrial Technology, Faculty of Applied Sciences, Universiti Teknologi MARA, 40450 Shah Alam, Selangor, Malaysia \\ ${ }^{3}$ Department of Chemical and Environmental Engineering, Faculty of Engineering, Universiti Putra Malaysia, \\ 43400 Serdang, Selangor, Malaysia \\ ${ }^{4}$ Department of Chemistry, Faculty of Science, Universiti Putra Malaysia, 43400 Serdang, Selangor, Malaysia \\ ${ }^{5}$ Radiation Processing Technology Division, Malaysian Nuclear Agency, 43000, Bangi, Malaysia
}

\section{* Corresponding author: \\ tel: $+603-89466288$ \\ email: tintahikmah@gmail.com; \\ chuah@upm.edu.my}

Received: November 21, 2017

Accepted: September 7, 2018

DOI: $10.22146 /$ ijc.30460

\begin{abstract}
This research aims to investigate the effect of crude palm oil (CPO) as a plasticizer in polypropylene blown film on thermal and dynamic mechanical properties. Polypropylene (PP) was blended with 1, 3, and 5\% of CPO using a twin screw extruder. The extruded samples were blown using the blown thin film technique. The samples were analyzed using dynamic mechanical analysis (DMA), differential scanning calorimetry (DSC) and thermogravimetric analysis (TGA). From the dynamic mechanical analysis, the storage modulus and loss modulus for PP presented decreasing pattern about 3-5\% due to the action of CPO as plasticizer which introduced free volume and enabled the polyolefins chains to deform more easily. The glass transition temperatures (Tg) of PP were found being shifted to lower temperature from 10 to $1{ }^{\circ} \mathrm{C}$ with the increasing $C P O$ content. The fraction of crystallization was determined using DSC. The thermogravimetric analysis (TGA) results showed that the incorporation of CPO as plasticizer showed a small increased effect in the thermal stability for PP. These findings have contributed new knowledge to the additives area and give important implications for designing and manufacturing polymer packaging materials.
\end{abstract}

Keywords: crude palm oil; polypropylene; plasticizer; thermal properties

\section{- INTRODUCTION}

Plastics, especially those used in packaging, contribute a large percentage to household wastes. One of the most important plastics groups is the polyolefin. Polymers and copolymers obtained from olefins, specifically polyethylene (PE) and polypropylene, which had been widely used and have great commercial success in the packaging industry. Polypropylene (PP), also known as polypropene, is a thermoplastic polymer used in a wide variety of applications including packaging and labeling, textiles (e.g., ropes, thermal underwear and carpets), stationery, plastic parts and reusable containers of various types, laboratory equipment, loudspeakers, automotive components, transvaginal mesh and many other products. Polypropylene is in many aspects similar to polyethylene, especially in solution behavior and electrical properties. The properties of polypropylene depend on the molecular weight and molecular weight distribution, crystallinity, type and proportion of comonomer (if used) and the isotacticity. In isotactic polypropylene, for example, the $\mathrm{CH}_{3}$ groups are oriented on one side of the carbon backbone. This creates a greater degree of crystallinity and results in a stiffer material that is more resistant to creep than both atactic polypropylene and polyethylene [1]. 
Plasticizer is defined as low molecular weight (MW) resins or liquids added to polymeric materials to improve their flexibility and other properties, which form secondary bonds to the polymer chain and spread them apart one another. The benefits of using plasticizer include lowering the glass transition temperature, reduction in brittleness of polymer, increase in flexibility, improvement of mechanical properties, reduce polymer crystallization, facilitate thermoplastic properties, improvement in impact resistance and tear resistance [23]. Role of plasticizer is to make the polymer further away from each other. As the polymer chains further away from one another, the strength of the intermolecular forces of attraction decreases. The polymer chains are also able to slide over the plasticizers so there is a fluidity to the structure. This makes the overall structure softer hence becomes a lot more flexible. According to the lubricity theory of plasticization, the function of plasticizer is to reduce intermolecular fiction between the polymer molecules [4]. Phthalate plasticizers are the most commonly used in the plastics industry. Two examples of phthalate plasticizers are DEHP (Di-Ethylhexyl Phthalate), and DINP (Di-Isononyl Phthalate). Plasticizers can be helpful for production, but they are potentially toxic and should not be used for food packaging applications for fear of migration into foods [5].

Plasticizers from biodegradable materials are gaining attention as a substitute for petroleum-based plasticizers which possess high toxicity and may consider unfriendly to the environment. Recently, crude or modified vegetable oils have gained a lot of interest as a renewable source of plasticizer for polymers [6]. Numerous research has been reported on the usage of epoxidized vegetable oil (EVO) as a plasticizer for the PLA [7-10]. There are some advantages using vegetable oil as a plasticizer in polymer industry such as biodegradable, environmental friendly and sustainable [11-12] have studied the physical properties of PE modified with the crude palm oil (CPO). The CPO give more competitive and cheap price compared to the petroleum-based plasticizer. The environmentally friendly and renewable $\mathrm{CPO}$ create a good potential as an alternative to the petroleum-based plasticizer. Their findings indicated that the $\mathrm{CPO}$ has a significant influence on the orientation strengthening on the HDPE and LLDPE. The presence of fibrils in stretch surfaces of HDPE and LLDPE that were incorporated with 5\% CPO evidence the orientation strengthening in the polymers. Jusoh et al. [13] also investigated the effect of CPO on the mechanical and morphology properties of low-density polyethylene (LDPE) blown film. The results on tensile properties were showed the gradual enhanced the elongation at break about 79 to $90 \%$ in the machine direction (MD) and transverse direction (TD) and gradually decreased the tensile strength about $9 \%$.

Indonesia and Malaysia are major producers of CPO which consists of 5.2 MMT of CPO in 2016 which contributing to about $85 \%$ of world palm oil production. Global palm oil has expanded at around $4 \%$ in the past six years up from 52.6 MMT in 2011 to 64.25 MMT in 2016 [14-15]. The palm oil contains unsaturated and saturated fatty acids having $40 \%$ oleic acid (monounsaturated fatty acid), 10\% linoleic acid (polyunsaturated fatty acid), 45\% palmitic acid and 5\% stearic acid (saturated fatty acid). The fatty acid chains present in the palm oil triglycerides could vary in the number of carbons present in the chain (chain length) and in structure (presence of double bonds). It is the variations in the structure and number of carbons in these fatty acid chains that largely define the chemical and physical properties of the palm oil [16]. The components obtained from the palm oil like monoglyceride and triglyceride are most suitable for plasticizer [17].

Blown film extrusion is the process by which most commodity and specialized plastic films are made for the packaging industry. The film blowing process basically consists of an extruding a tube of molten thermoplastic and continuously inflating it to several times the initial diameter, to form a thin tubular product that can be used directly, or slit to form a flat film. Plastic melt is extruded through an annular slit die, usually vertically, to form a thin walled tube. Air is introduced via a hole in the center of the die to blow up the tube like a balloon [18]. 


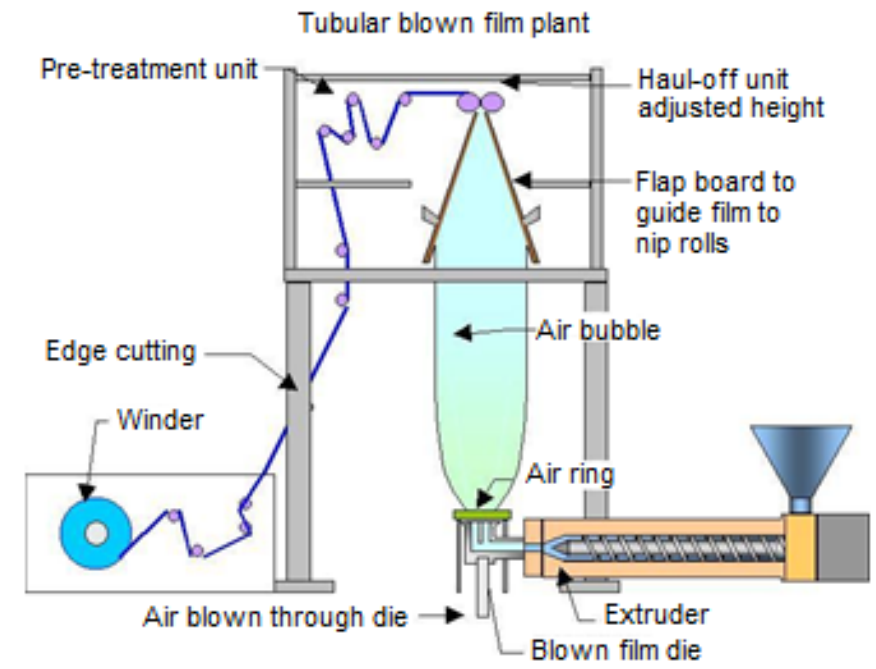

Fig 1. The blown thin film process generally used for polyethylene [19]

Mounted on top of the die, a high-speed air ring blows onto the hot film to cool it. The tube of the film then continues upwards, continually cooling, until it passes through nip rolls where the tube is flattened to create what is known as a lay-flat tube of film. This lay-flat or collapsed tube is then taken back down the extrusion tower via more rollers. On higher output lines, the air inside the bubble is also exchanged [18]. Fig. 1 shows the blown thin film process generally used for PE and PP.

Polypropylene (PP) is generally quite difficult to convert into a film on the conventional upward blown film extrusion mainly due to poor melt strength, long cooling time and somewhat inferior optical properties. There are two methods are widely used for producing biaxially oriented PP film. One is the tenter process, and the other is the tubular or bubble process [20]. In the tenter process, extruded sheet is drawn sequentially, first in the machine direction and then in the transverse or cross direction. In the tubular process, a tube is extruded downward through an annular die over a mandrel that cools the tube. The tube is taken up through a water bath or air cooling for further cooling. The flat tube is moved by rolls through an oven where it is reheated to a temperature close to the melting temperature. The tube is then inflated while being stretched in the machine direction, imparting orientation through roughly six-fold biaxial stretching. PP is used in packaging products such as films, molded container, and cushioning. The packaging materials benefit greatly from the inclusion of additives to polymers to enhance processability and performance [21]. In the recent year, there has been a large increase in the use of oriented PP for food packaging. Polymer additives such as plasticizer have an essential effect on packaging materials. The ability to modify polymers has allowed the packaging industry to produce better and stronger materials [22]. PP blown thin film has better mechanical properties include tensile, flexural strength and toughness because it is drawn in both orientation of transverse and machine direction. These uniform properties in both directions allow for maximum toughness in the application for packaging materials. Nowadays, polymers both natural and synthetic rely on additives for processing. Additives and polymer resins are mixed created new blends to produce improved materials. The inclusion of polymer additives allows manufacturers to create individualized blends and get a very specialized product to satisfy customers' needs. For the PP packaging industry, this means better materials are available with an increased capacity to create a unique blend for products with specific requirements. The use of $\mathrm{CPO}$ as an additive in packaging processing can provide a cheaper and effective solution to achieving the necessary chemical and physical property improvements [23].

A study by Ratnam et al. [12] revealed an influence of a small amount of CPO content on the physical properties of HDPE and LLDPE has shown an improvement in tensile strength and elongation at break with a concurrent decline in density implied the enhancement in toughness of the polymers. A gradual increase in impact strength of HDPE with the CPO content further supported the notation above. In other research on palm cooking oil as processing aids in LDPE blend with tapioca starch has shown that incorporation of palm oil gave higher melt flow index (MFI) as the viscosity of the blend was decreased and the processability was expected to be improved [24]. The thermal stability of blends also improved by the addition of palm oil compared to the glycerol. This means the palm oil incorporation with polymer could give better performance in rheology and thermal stability which 
could help to substitute the usage of expensive glycerol for processing aids additive. Research by Norazlin et al. [25] on PP modified with palm oil has shown significant effects of palm oil as an additive to the PP. PP is a nonbiodegradable polymer and efforts had been done to degrade the PP through various techniques. Oxodegradation additives had been based on metal salt complex. The effect of these additives is to degrade PP into smaller molecular weight fragments which can be digested by microbes and enzymes for easy assimilation to the soil. Palm oil has been used because it has polyunsaturated and unsaturated fatty acids, is natural and available abundantly and can perhaps be useful as oxodegradant [25].

The characterization and mechanical properties for CPO-filled polypropylene blown film had been reported by Jusoh et al. [26]. However, no study has been reported on the thermal properties on CPO-filled polypropylene blown film. Due to the thermoplastic materials can undergo various types of dynamic stressing during service, studies on the dynamic mechanical properties of these materials are also of great importance. Furthermore, because of the highly temperature-dependent mechanical properties of such polymers, the application of a method that monitors property changes over a range of temperatures is critical. Dynamic mechanical analysis (DMA) is a sensitive technique that characterizes the mechanical responses of materials by monitoring property changes with respect to temperature and/or frequency of oscillation. The technique separates the dynamic response of materials into two distinct parts: an elastic part (E') and a viscous or damping component (E"). The elastic process describes the energy stored in the system, whereas the viscous component describes the energy dissipated during the process. DMA provides a rapid assessment of the rheological properties of these materials. The objectives of this study were to investigate the influence of CPO contents on the rheological properties and phase transitions of LDPE using DMA. The information developed from this study would have important implications for production and manufacturing in the plastic industry.
Table 1. Data of crude palm oil used in this study

\begin{tabular}{lc}
\hline Properties & Value \\
\hline Free fatty acid (\%) & 3.79 \\
Peroxide value (meq/kg) & 2.80 \\
Anisidine value & 3.30 \\
Carotenoids (ppm) & $>600$ \\
Deterioration of Bleachability Index (DOBI) & 2.70 \\
Iodine Value & 52.50 \\
Saponification Value & 197 \\
Moisture and impurities (\%) & 0.25 \\
Unsaponifiable matter (\%) & 0.70 \\
Melting point $\left({ }^{\circ} \mathrm{C}\right)$ & 36.50 \\
Copper $(\mathrm{ppm})$ & 0.12 \\
Iron $(\mathrm{ppm})$ & 4.20 \\
Phosphatides $(\mathrm{ppm})$ & 694 \\
\hline
\end{tabular}

\section{- EXPERIMENTAL SECTION}

\section{Materials}

The PP resins (Propelinas I112) used in this study were obtained from Polypropylene Malaysia Sdn Bhd, Gebeng, Malaysia. The density and melt flow index (at temperature $230{ }^{\circ} \mathrm{C}$, and load $2.16 \mathrm{~kg}$ ) of PP resin are $0.92 \mathrm{~g} / \mathrm{cm}^{3}$ and 5.0. The properties of the materials used in this study are as listed in Table 1 . The crude palm oil used was obtained in liquid form directly from the factory Palong Cocoa Palm Oil Mill, Johor, Malaysia.

\section{Procedure}

\section{Formulations and compounding}

The CPO:PP compounds were prepared by mixing the PP resins with 1, 3, and 5 wt.\% CPO. A sample of PP without $\mathrm{CPO}$ was used as controls. PP and CPO were dry blended in a tumbler mixer for $30 \mathrm{~min}$. Melt blending was carried out in a Brabender twin-screw extruder PL 2100-3 model (DSK 42/6 D). The temperatures of the three zones of the extruder were 190,185 , and $180^{\circ} \mathrm{C}$, respectively. The samples were fed into an extruder hopper and the extrudates were passed through a coldwater bath of $20^{\circ} \mathrm{C}$. The extrudate was then palletized and dried.

\section{Preparations of blown films}

The CPO:PP granules obtained by extrusion were transformed into film using conventional blowing film 
Table 2. Blowing parameter of $\mathrm{PP} / \mathrm{CPO}$

\begin{tabular}{cccccc}
\hline Sample & \multicolumn{2}{c}{$\begin{array}{c}\text { Extruding drum heater } \\
\text { temperature }\left({ }^{\circ} \mathrm{C}\right)\end{array}$} & $\begin{array}{c}\text { Screw speed } \\
(\mathrm{rpm})\end{array}$ & $\begin{array}{c}\text { Die head heater } \\
\text { temperature }\left({ }^{\circ} \mathrm{C}\right)\end{array}$ \\
\hline $\mathrm{PP}($ control) & 170 & 180 & 200 & $600-900$ & $175^{\circ} \mathrm{C} / 150^{\circ} \mathrm{C}$ \\
$\mathrm{PP}: 1 \% \mathrm{CPO}$ & 170 & 180 & 200 & $600-900$ & $175^{\circ} \mathrm{C} / 150^{\circ} \mathrm{C}$ \\
$\mathrm{PP}: 3 \% \mathrm{CPO}$ & 170 & 180 & 200 & $600-900$ & $175^{\circ} \mathrm{C} / 150^{\circ} \mathrm{C}$ \\
$\mathrm{PP}: 5 \% \mathrm{CPO}$ & 170 & 180 & 200 & $600-900$ & $175^{\circ} \mathrm{C} / 150^{\circ} \mathrm{C}$ \\
\hline
\end{tabular}

equipment (Brabender Blower PL 2100-3). Film specimens were prepared using sheet extrusion with slit die (single screw extruder, 19/25D). The blowing conditions employed for PP/CPO is listed in Table 2. Fig. 2(a) and 2(b) showed the tubular blowing film equipment and a part of the process. In this process, the film is stretched biaxially. Extruded sheets were pulled using take-up of the device and the film thickness was maintained at about $0.03-0.07 \mathrm{~mm}$. The specimens were cut from the film in accordance to specimen preparation method for testing. After preparation, all specimens were conditioned in a humidity-controlled room at $23{ }^{\circ} \mathrm{C}$ and $50 \%$ relative humidity for at least $40 \mathrm{~h}$ prior to performing DMA tests.

\section{Melt flow index}

LDPE/CPO and PP/CPO blends were evaluated for MFI tested on the Zwick 4105 Extrusion Plastometer by Zwick Materials Testing brand based on ASTM D 1238 [27]. It is expressed as $\mathrm{g} / 10 \mathrm{~min}$ at $190{ }^{\circ} \mathrm{C}$, under a $5 \mathrm{~kg}$ load.

\section{Thermogravimetric analysis (TGA)}

Thermogravimetric Analysis (TGA) was used to analyze the thermal stability of the formulations during exposure to a specified environment using a controlled time rate of heating, in accordance to ASTM D 3850. Weight loss of polymer samples as a function of temperature is commonly determined by thermo gravimetric analysis (TGA) technique and is an irreversible process due to thermal degradation. The thermal stability of polyolefins modified with $\mathrm{CPO}$ was tested by measuring their thermal decomposition temperature at the onset and end of weight loss. Higher decomposition temperature means better thermal stability for the blends [10]. Thermogravimetric analysis (TGA) was performed in Mettler Toledo TGA equipment. A sample of about 6 to $12 \mathrm{mg}$ was placed in the specimen holder and the initial mass was recorded and the heating rate was set to $10{ }^{\circ} \mathrm{C} / \mathrm{min}$ from room temperature to $700{ }^{\circ} \mathrm{C}$.

\section{Differential scanning calorimetry (DSC) measurement}

The differential scanning calorimetry (DSC) measurements were performed in a Perkin-Elmer DSC 7. DSC was calibrated with indium standard prior to use. About $0.78-0.82 \mathrm{mg}$ of the samples were first heated from room temperature to $200{ }^{\circ} \mathrm{C}$ at $10{ }^{\circ} \mathrm{C} / \mathrm{min}$ and held there for $5 \mathrm{~min}$ to remove the thermal history, and cooled to room temperature at $10^{\circ} \mathrm{C} / \mathrm{min}$ to record the crystallization behavior, and then reheated to $200{ }^{\circ} \mathrm{C}$ at $20^{\circ} \mathrm{C} / \mathrm{min}$ to trace the melting behaviour. The melting temperature, Tm $\left({ }^{\circ} \mathrm{C}\right)$, was determined as the peak temperature The enthalpy of fusion $\left(\Delta \mathrm{H}_{\mathrm{f}}\right)$ was determined from the area of DSC endotherm. The heat of fusion of polymer samples could be used to determine the mass fraction crystallinity, $\mathrm{x}_{\mathrm{c}}(\%)$ as shown in the relationship equation (1).

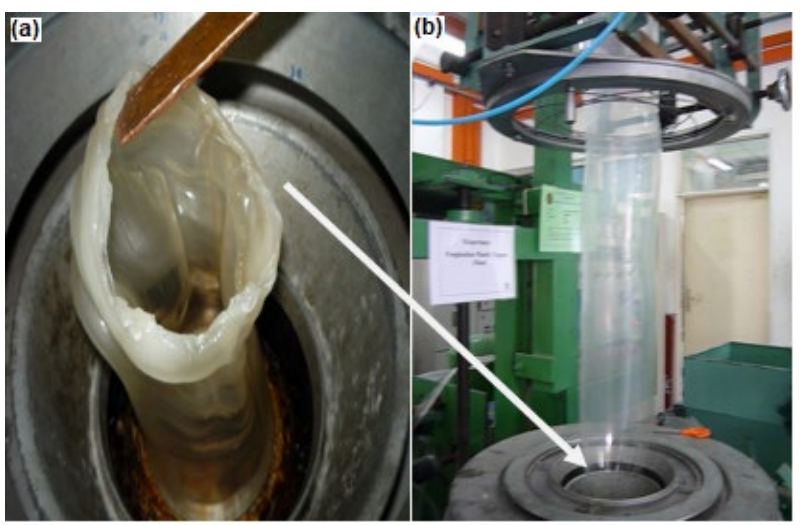

Fig 2. (a) close up of the extruded melt sample from a circular die. (b) blown up large polyolefin tubular film and the picked up by a pair of nip rolls 


$$
\mathrm{x}_{\mathrm{c}}=\frac{\Delta \mathrm{H}_{\mathrm{f}}}{\Delta \mathrm{Hf}^{\circ}}
$$

\section{Dynamic mechanical analysis (DMA)}

DMA was performed for individual specimens using a DMA7 (Perkin Elmer Corp., High Wycombe, UK) with a three points bending. Samples were equilibrated at -150 until $90^{\circ} \mathrm{C}$ and purged with helium $\left(20 \mathrm{~mL} \mathrm{~min}^{-1}\right)$ during testing. In the first step of this work, some preliminary tests were carried out in order to observe the variability of the experimental results in experiments performed under the same repeated conditions and for the same material. These conditions were, sample CPO: PP, frequency $1 \mathrm{~Hz}$, dynamic force $100 \mathrm{~N}$, static force $110 \%$ of the dynamic force, distance between supports $15 \mathrm{~mm}$, sample width $10 \mathrm{~mm}$, sample thickness $0.9-1.0 \mathrm{~mm}$, sample length 15 $\mathrm{mm}$, minimum temperature $-150{ }^{\circ} \mathrm{C}$, maximum temperature $90{ }^{\circ} \mathrm{C}$, heating rate $10^{\circ} \mathrm{C} / \mathrm{min}$, nitrogen flow pressure 0.5 bar.

\section{- RESULTS AND DISCUSSION}

\section{MFI of PP Blown Film Modified with CPO}

Fig. 3 shows MFR values of PP and blends of PP and $\mathrm{CPO}$ as a plasticizer. The melt flow rate of PP incorporation with $5 \% \mathrm{CPO}$ is $12.7 \mathrm{~g} / 10 \mathrm{~min}$ compared to neat $\mathrm{PP}$ with $11.8 \mathrm{~g} / 10 \mathrm{~min}$, respectively. This shows that the MFR value of PP blends with CPO has indicated higher value than that of neat PP MFR. This indicates that the incorporation of $\mathrm{CPO}$ has increased the melt flow rate of the blends compared to the neat PP. This observation indicated that the incorporation of $\mathrm{CPO}$ which reacted as plasticizer has decreased the intermolecular forces between polymer coils and has increased the molecular space [28-29] and mobility of polymer has resulted in the increase of MFR. This indicates that the viscosity of the blend has decreased with the addition of CPO. As the viscosity of the PP modified with $\mathrm{CPO}$ decreased the processability was expected to be improved.

\section{Thermogravimetric Analysis (TGA)}

The TGA and derivative thermogravimetric (DTG) curves of PP modified with CPO show in Fig. 4(a) and 4(b). It is observed that the weight loss of pure PP occurred in a one-step degradation process from 400 to $500{ }^{\circ} \mathrm{C}$. This result can be confirmed by the presence of only one peak in the derivative thermogravimetric curve (DTG) temperature at nearly $445{ }^{\circ} \mathrm{C}$ (Table 3). This result indicated that $\mathrm{PP}$ is composed of the carboncarbon bonds in the chain, thereby allowing a temperature increase to promote random scission with associated thermal degradation and thermal depolymerization occurring at the weak sites of the PP main chains [30-31]. The mass loss of pure PP takes place very slowly at temperatures below $400{ }^{\circ} \mathrm{C}$. However,

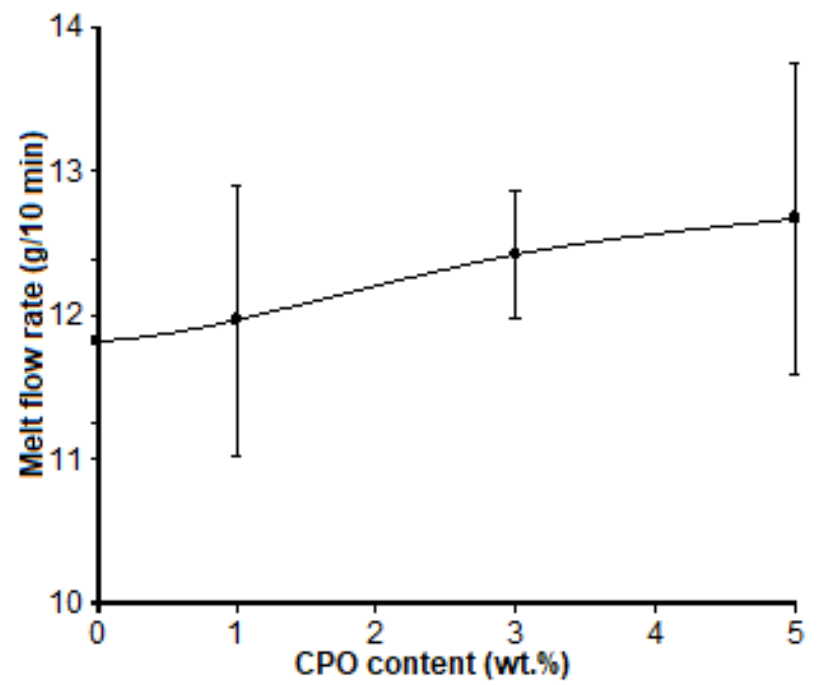

Fig 3. Effect of CPO content on the melt flow rate of PP

Table 3. TGA data collection for PP modified with CPO varying content

\begin{tabular}{cccccc}
\hline Sample & $\begin{array}{c}\text { The residue at } \\
\text { the first step }(\%)\end{array}$ & $\begin{array}{c}\text { Onset temp } \\
\left({ }^{\circ} \mathrm{C}\right)\end{array}$ & $\begin{array}{c}\text { Midpoint temp } \\
\left({ }^{\circ} \mathrm{C}\right)\end{array}$ & $\begin{array}{c}\text { Endset temp } \\
\left({ }^{\circ} \mathrm{C}\right)\end{array}$ & $\begin{array}{c}\text { Final residue } \\
(\%)\end{array}$ \\
\hline $\mathrm{PP}$ & 98.62 & 300.15 & 459.75 & 517.08 & 1.54 \\
$\mathrm{PP} / 1 \% \mathrm{CPO}$ & 99.13 & 315.15 & 461.90 & 539.53 & 1.82 \\
$\mathrm{PP} / 3 \% \mathrm{CPO}$ & 98.90 & 325.50 & 463.86 & 547.27 & 1.76 \\
$\mathrm{PP} / 5 \% \mathrm{CPO}$ & 99.12 & 338.18 & 466.83 & 549.12 & 1.51 \\
\hline
\end{tabular}



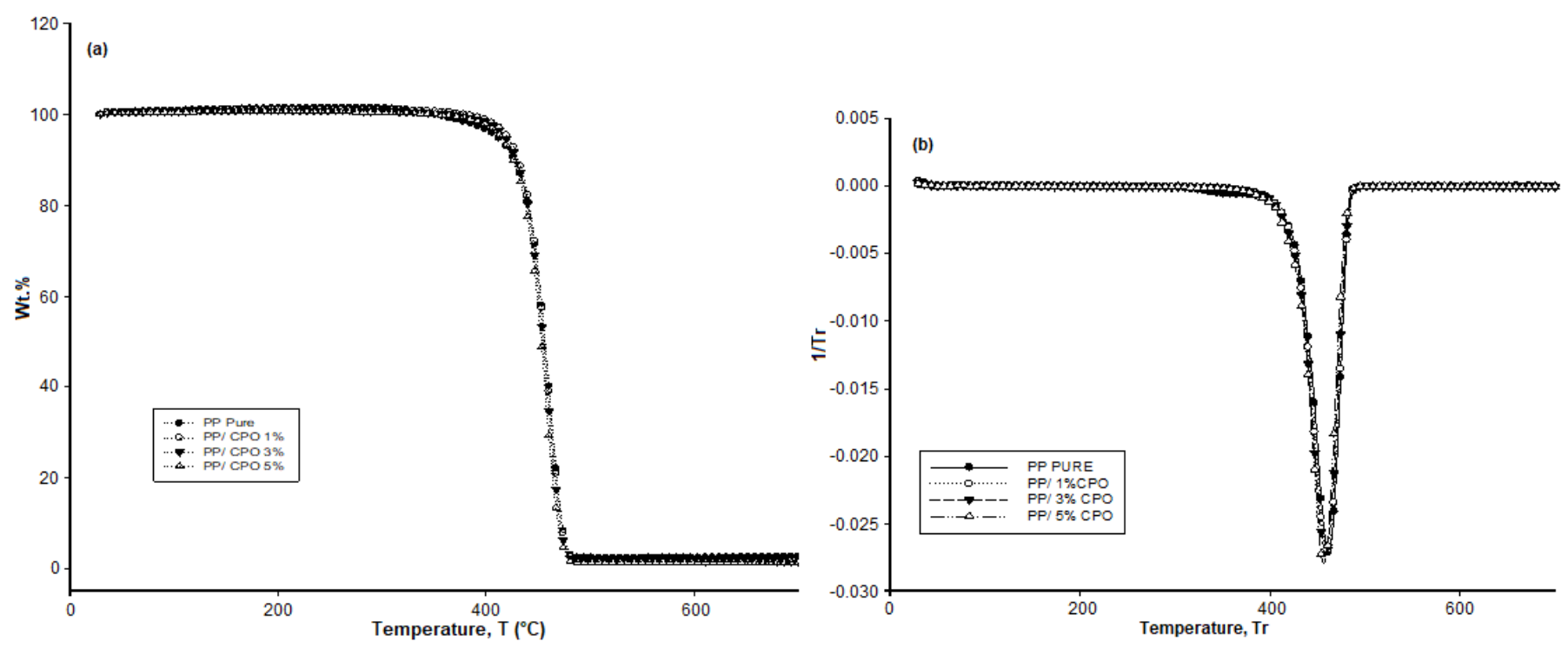

Fig 4. Thermograms of PP modified with varying CPO content (A) TG, and (B) Derivatives TG

at a temperature above $400{ }^{\circ} \mathrm{C}$, this process occurs very rapidly and the quantity of $\mathrm{PP}$ residue is very small due to further breakdown of PP into the gaseous product at a higher temperature. Among the modified PP, it is observed that the decomposition temperature gradually increases with an increase in the CPO content (Fig. 4(a)). However, the TGA thermographs showed an insignificant increase on the thermal stability of PP modified with CPO due to the very small amount of CPO content was added. This plasticization of the polymer network provides more stability to the matrix and hence the polymer samples show an increase in the decomposition temperature with an increase in the oil content [32].

\section{Dynamic Mechanical Analysis (DMA)}

Fig. 5 presents the temperature dependence storage modulus of PP at $0,1,3$, and $5 \%$ of CPO loading. It shows that the storage modulus of the modified PP is lower than neat $\mathrm{PP}$ at a lower temperature $\left(-40{ }^{\circ} \mathrm{C}\right)$ to a higher temperature $\left(100{ }^{\circ} \mathrm{C}\right)$. There was a large drop in the storage modulus around -20 to $20^{\circ} \mathrm{C}$ corresponding to the glass transition region. It can be seen that at $0{ }^{\circ} \mathrm{C}$ all of the polymers in the transition from the glassy region to the rubbery plateau.

The loss modulus of pure PP and PP modified with the various loading of $\mathrm{CPO}$ are shown in Fig. 6. In the case

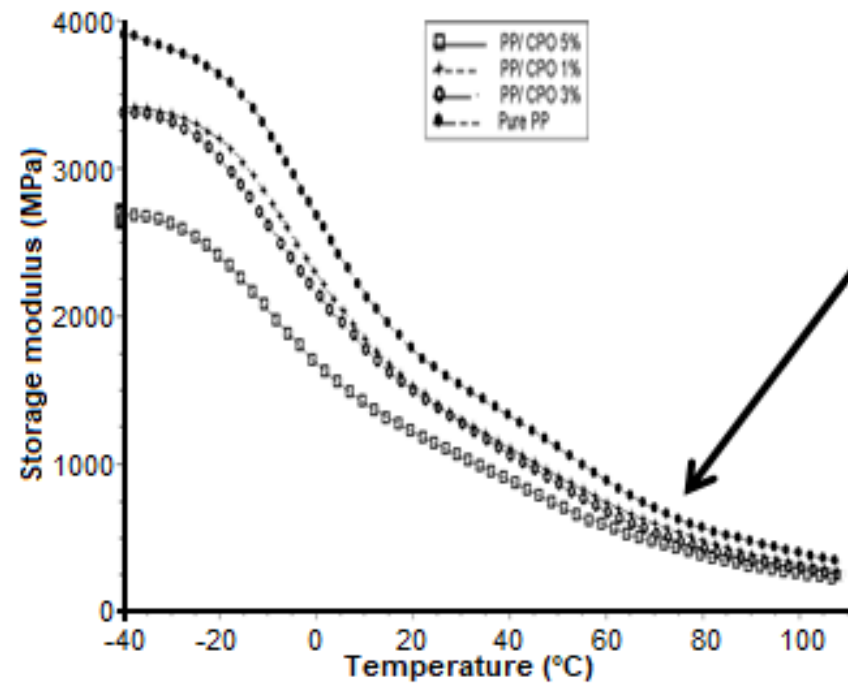

Fig 5. Effect of CPO loading on storage modulus of PP modified with $\mathrm{CPO}$

of pure PP, a sharp increase in the loss modulus peak is observed around $5{ }^{\circ} \mathrm{C}$. This said to be the $\beta$-transition which corresponding to the $\mathrm{Tg}$. This transition was shifted to an upper temperature between -5 to $-20{ }^{\circ} \mathrm{C}$ for neat PP compared to PP modified with 1, 3, and 5\% CPO. The $\alpha$-relaxation peak can be seen between 55 and $75{ }^{\circ} \mathrm{C}$ for the neat PP and PP modified CPO. The addition of $\mathrm{CPO}$ in the polymer matrix are showed significantly lowering the glass transition temperature of PP. These findings are consistent with the fundamental 


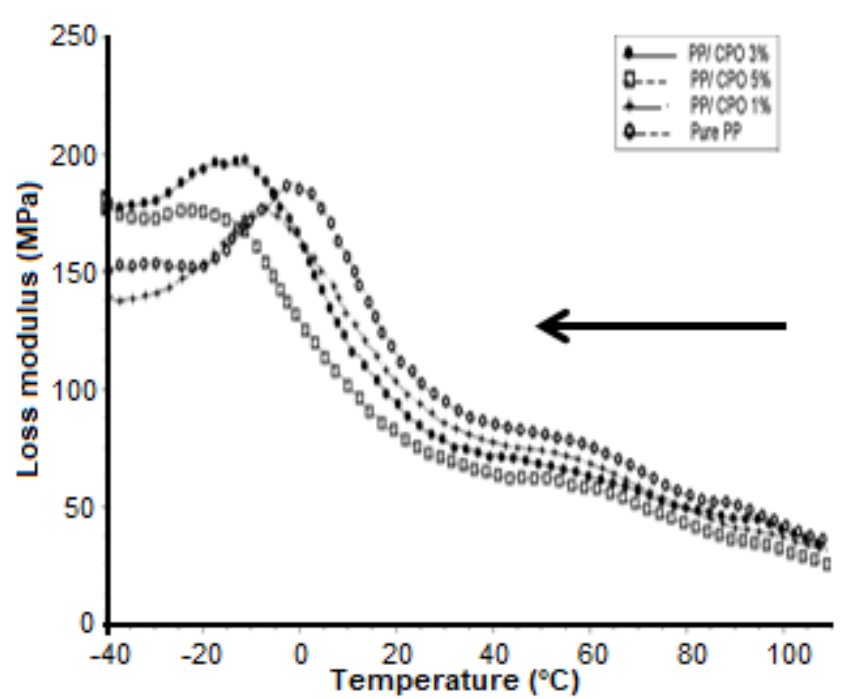

Fig 6. Effect of CPO loading on loss modulus of PP modified with $\mathrm{CPO}$

molecular effect of a plasticizer which is to interact with the segments of the polymer to speed up the viscoelastic response of PP. Thus, a plasticizer increases the mobility of the chains and results in a lowering glass transition temperature.

The effect of CPO loading content on mechanical loss spectra $(\tan \delta)$ of neat PP and PP modified with CPO are shown in Fig. 7. The shift in $\beta$-transition (glassrubbery transition) to the lower temperature $\left(-5\right.$ to $\left.-15^{\circ} \mathrm{C}\right)$ can be observed from both the PP and PP blends. It is due to the glass transition of the amorphous polymer in this semi-crystalline material (PP). It is the temperature where the polymer goes from glassy to rubbery states. At the $\mathrm{T}_{\mathrm{g}}$ conversion of glassy (amorphous) solid to rubbery (viscous liquid) takes place. The increase of $\mathrm{CPO}$ contents has shifted the $\mathrm{T}_{\mathrm{g}}$ to lower temperature, hence, increase the elasticity of the system. The lower $\tan \delta$ values associated with the $\mathrm{T}_{\mathrm{g}}$ temperature reflects the improved of the system in which a reduction in damping occurs with

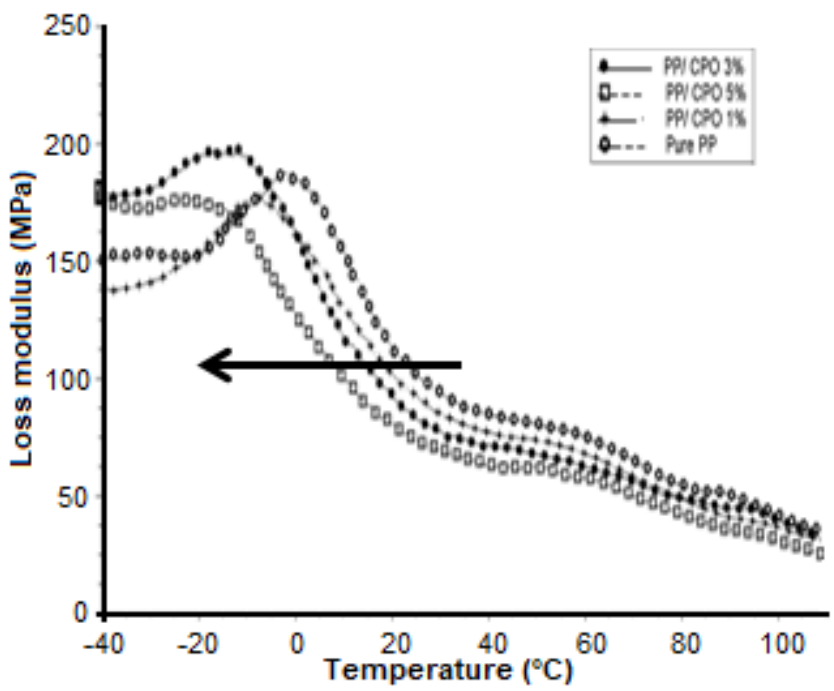

Fig 7. Effect of CPO loading on the tan delta of PP modified with $\mathrm{CPO}$

the increase of CPO content. It is also evident that the $\alpha$ transition, which was seen in loss modulus spectra is not clearly seen here, indicating that this transition is not a major transition in pure PP or its blends. The summary of glass transition temperature for PP was showed in Table 4.

\section{Differential Scanning Calorimetry (DSC)}

The crystallization and melting behavior from DSC second heating scans were shown in Fig. 8 and 9. The DSC melting curves of pure PP and PP/CPO blends (Fig. 8) shows only one endothermic peak with a slight

Table 4. Summary of glass transition temperature (Tg) of PP modified with CPO

\begin{tabular}{cc}
\hline Sample & Glass transition temp $\left({ }^{\circ} \mathrm{C}\right)$ \\
\hline $\mathrm{PP}$ & 9.83 \\
$\mathrm{PP} / 1 \% \mathrm{CPO}$ & 7.54 \\
$\mathrm{PP} / 3 \% \mathrm{CPO}$ & 4.51 \\
$\mathrm{PP} / 5 \% \mathrm{CPO}$ & 1.32 \\
\hline
\end{tabular}

Table 5. The specific melting enthalpy $\left(\Delta \mathrm{H}_{\mathrm{m}}\right)$, melting temperature $\left(\mathrm{T}_{\mathrm{m}}\right)$, the degree of crystallinity $\left(\mathrm{x}_{\mathrm{c}}\right)$, crystallinity temperature $\left(\mathrm{T}_{\mathrm{c}}\right)$ of $\mathrm{PP} / \mathrm{CPO}$

\begin{tabular}{cccccc}
\hline Sample & $x_{\mathrm{c}}(\%)$ & $\mathrm{T}_{\mathrm{c}}\left({ }^{\circ} \mathrm{C}\right)$ & $\mathrm{Tm}\left({ }^{\circ} \mathrm{C}\right)$ & $\Delta H_{m}(\mathrm{~J} / \mathrm{g})$ & $\Delta \mathrm{Hc}(\mathrm{J} / \mathrm{g})$ \\
\hline $\mathrm{PP}$ & 65.72 & 122.78 & 161.70 & -138.44 & 136.11 \\
$\mathrm{PP} / 1 \% \mathrm{CPO}$ & 50.87 & 121.28 & 164.21 & -102.59 & 105.37 \\
$\mathrm{PP} / 3 \% \mathrm{CPO}$ & 50.65 & 117.44 & 164.81 & -104.89 & 104.89 \\
$\mathrm{PP} / 5 \% \mathrm{CPO}$ & 47.72 & 114.94 & 164.98 & -102.12 & 98.83 \\
\hline
\end{tabular}




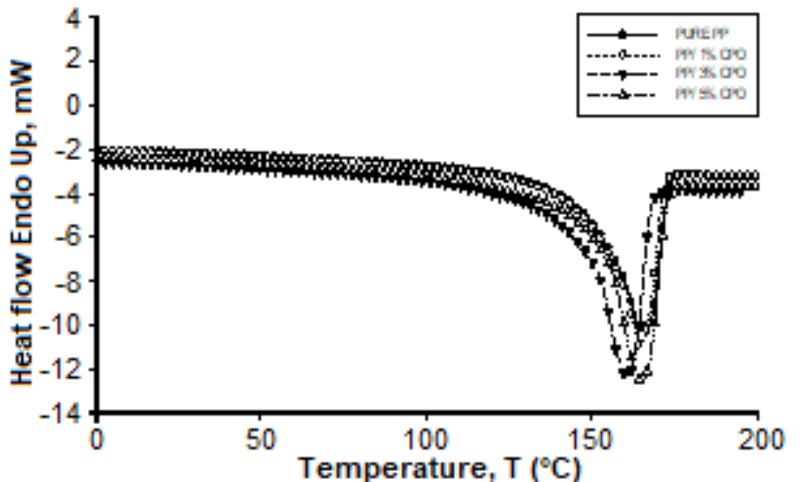

Fig 8. DSC curves of heating for PP and PP modified with $\mathrm{CPO}$

increase in the melting peak temperature when CPO is added to PP. So, with the addition of CPO, the melting point did not appear substantially affected. As seen, the melting points were very close to each other and the recorded differences are within the range of experimental error. Fig. 9 shows the DSC cooling curve of pure PP and $\mathrm{PP} / \mathrm{CPO}$ blends. Cooling curves from DSC indicate alterations in the crystallization behavior (crystallization temperature) of PP upon addition of CPO. The results showed that the crystallization temperatures were significantly decreased with the increase of CPO content. The values of crystallization temperature can be noted in Table 5. The degree of crystallinity of modified with CPO was calculated and showed the decreasing pattern. This observation can again be explained that the CPO act as nucleation sites for the crystallization and destroyed the crystalline in the PP matrix. It may be assumed that the nucleating effect considerably contributes to the occurrence of transcrystalline layers around the $\mathrm{CPO}$ as the lubricating effect on PP [33].

\section{- CONCLUSION}

From the dynamic mechanical analysis (DMA), the decrement in storage modulus of PP with incorporating $\mathrm{CPO}$ indicated that plasticizing effect of $\mathrm{CPO}$ occurred in the polymers. The loss modulus of modified LDPE was decreased attributed to a factor of plasticisation which the $\mathrm{CPO}$ act as plasticiser to introduce free volume and enable the network. Tg of PP was shifted to a lower temperature with the increasing of CPO content in the blends. DSC measurement showed that the addition of CPO has

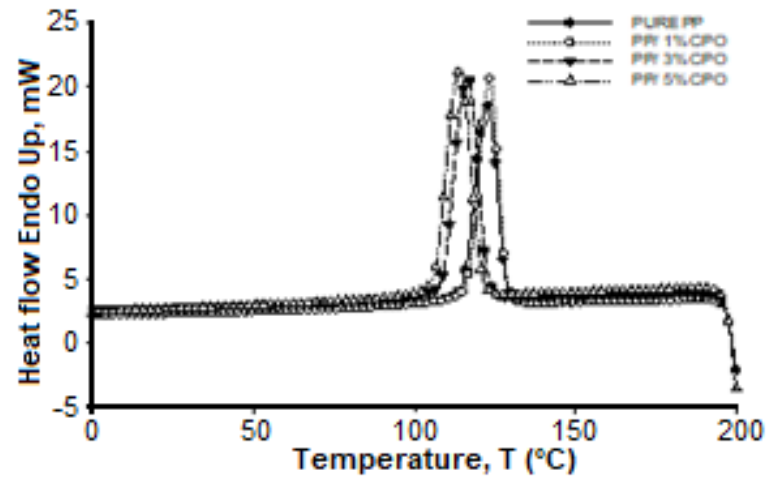

Fig 9. DSC curves of cooling for PP and PP modified with $\mathrm{CPO}$

gradually increased the degree of crystallinity of $\mathrm{PP}$ matrices. Thermogravimetric Analysis (TGA) showed that the thermal stability was gradually increased with the addition of $\mathrm{CPO}$ content in both polyolefins due to the presence of small amount CPO. The plasticizing effect of CPO in PP was investigated and proved that the plasticization mechanism occurred in the polymer systems.

\section{ACKNOWLEDGMENTS}

The authors would like to thank Universiti Putra Malaysia (UPM) for the support and the Ministry of Higher Education, Malaysia for their funding of Fundamental Research Grant Scheme (FRG-GSP, UPM/700-2/1/FRGS/GSP/5524868).

\section{- REFERENCES}

[1] Karian, H.G., 2003, Handbook of Polypropylene and Polypropylene Composites, $2^{\text {nd }}$ ed., Marcel Dekker, Canada, 57-68.

[2] Ho, C.H., Wang, C.H., Lin, C.I., and Lee, Y.D., 2008, Synthesis and characterization of TPO-PLA copolymer and its behavior as compatibilizer for PLA/TPO blends, Polymer, 49 (18), 3902-3910.

[3] Liao, H.T., and Wu, C.S., 2009, Preparation and characterization of ternary blends composed of polylactide, poly( $\varepsilon$-craptolactone) and starch, Mater. Sci. Eng., A, 515 (1-2), 207-214.

[4] Marcilla, A., and Beltran, M., 2004, "Mechanisms of Plasticizers Action" in Handbook of Plasticizers, 
Eds., Wypych, G., ChemTec Publishing, Toronto, Canada, 107-120.

[5] Wilson, A., 1995, Plasticizers Principles and Practice, $1^{\text {st }}$ ed., The Institute of Materials, London, 45-50.

[6] Robertson, M.L., Chang, K., Gramlich, W.M., and Hillmyer, M.A., 2010, Toughening polylactide with polymerized soybean oil, Macromolecules, 43 (4), 1807-1814.

[7] Alam, J., Alam, M., Raja, M., Abduljaleel, Z., and Daas, L.A., 2014, MWCNTs-reinforced epoxidized linseed oil plasticized polylactic acid nanocomposite and its electroactive shape memory behavior, Int. J. Mol. Sci., 15 (11), 19924-19937.

[8] Chieng, B.W., Ibrahim, N.A., Then, Y.Y., and Loo, Y.Y., 2017, Epoxidized jatropha oil as a sustainable plasticizer to poly(lactic acid), Polymer, 9 (6), 204.

[9] Dai, X., Xiong, Z., Na, H., and Zhu, J., 2014, How does epoxidized soybean oil improve the toughness of microcrystalline cellulose filled polylactide acid composites?, Compos. Sci. Technol., 90, 9-15.

[10] Al-Mulla, E.A.J., Suhail, A.H., and Aowada, S.A., 2011, New biopolymer nanocomposites based on epoxidized soybean oil plasticized poly(lactic acid)/fatty nitrogen compounds modified clay: Preparation and characterization, Ind. Crops Prod., 33 (1), 23-29.

[11] Al-Mulla, E.A.J., Wan Yunus, W.M.Z., Ibrahim, N.A., and Rahman, M.Z., 2010, Properties of epoxidized palm oil plasticized polytlactic acid, $J$. Mater. Sci., 45 (7), 1942-1946.

[12] Ratnam, C.T., Min, A.M., Chuah, T.G., Suraya, A.R., Choong, T.S.Y., and Wan Hasamuddin, W.H., 2006, Physical properties of polyethylene modified with crude palm oil, Polym. Plast. Technol. Eng., 45 (8), 917-922.

[13] Jusoh, E.R., Ismail, M.H.S., Chuah, A.L., Yunus, R., and Wan Abdul Rahman, W., 2013, Effect of crude palm oil as plasticizer on the mechanical and morphology properties of low-density polyethylene blown film, Int. J. Mater. Eng. Innovation, 4 (3-4), 302-313.

[14] Malaysia Palm Oil Board (MPOB). 2017, Malaysian Oil Palm Industry Performance 2016 and Prospects for 2017, http://www.mpob.gov.my/images/stories/ pdf/2017/2017__Dr.KushairiPALMEROS2017.pdf.

[15] Fadhil, H., 2018, Indonesia Palm Oil Industry: Current Status and Outlook 2018, Globoil International 2018, 27-29 ${ }^{\text {th }}$ April 2018, JW Marriott Marquis, Dubai.

[16] Yusof, B., 2005, "Vegetable Oils in Production of Polymers and Plastics" in Bailey's Industrial Oil and Fat Products, Eds., Shahidi, F., John Wiley, 339.

[17] Wypych, G., 2004, "Effect of Plasticizer on Properties Plasticized Materials" in Handbook of Plasticizers, Eds., Wypych, G., ChemTec Publishing, Toronto, Canada.

[18] Breil, J., 2014, "Biaxial Oriented Film Technology" in Film Processing Advances, $2^{\text {nd }}$ ed., Eds., Toshitaka, K., and Campbell, G.A., Carl Hanser Verlag, Germany, 193-229.

[19] Blown Film extrusion, http://aluminum extrusionss.com/2011/05/13/blown-film-extrusion/, accessed on, May 13, 2011.

[20] Kissel, W.J., Han, J.H., and Meyer, A.J., 2003, "Propylene: Structure, Properties, Manufacturing Processes, and Applications" in Handbook of Polypropylene and Polypropylene Composites, Eds., Karian, H.G., $2^{\text {nd }}$ ed., Marcel Dekker, Canada, 1134.

[21] Soroka, W., 2002, Fundamentals of Packaging Technology, $3^{\text {rd }}$ ed., Naperville, IL: Institute of Packaging Professionals.

[22] Murphy, J., 2001, Additives for Plastics, $2^{\text {nd }}$ ed., Elsevier Science Inc., New York, USA.

[23] Bart, J.C.J., 2005, "A Vision for the Future" in Additives in Polymers: Industrial Analysis and Applications, John Wiley \& Sons Ltd., London, 712.

[24] Roshafima, R.R., and Aizan, W.A.R.W., 2009, Mechanical and Biodegradation Studies of Low Density Polyethylene (LDPE)/Starch Based Film, The $3^{\text {rd }}$ International Conference on Chemical and Bioprocess Engineering, Universiti Malaysia Sabah, Kota Kinabalu, Sabah.

[25] Norazlin, R., Rahmah, M., Hairaini, T., Radin, S.F., and Hirzin, N.B., 2008, Determination of Avrami Exponent and Kinetics of Crystallization for Palm 
Oil Filled Polypropylene using Differential Scanning Calorimetry (DSC), The National Symposium of Polymeric Materials, Naza Hotel, Penang, Malaysia.

[26] Jusoh, E.R., Ismail, M.H.S., Abdullah, L.C., Yunus, R., and Wan Abdul Rahman, W.A., 2012, Crude palm oil as a bioadditive in polypropylene blown film, BioResources, 7 (1), 859-867.

[27] ASTM D 1238, 2001, Standard Test Method for Melt Flow Rates of Thermoplastics by Extrusion Plastometer, ASTM International, USA.

[28] Prachayawarakorn, J., and Yaembunying, N., 2005, Effect of recycling on properties rice husk-filledpolypropylene, Songklanakarin J. Sci. Technol., 27 (2), 344-352.

[29] Audic, J.L., and Chaufer, B., 2005, Influences of plasticizers and crosslinking on the properties of biodegradable films made from sodium casienate, Eur. Polym. J., 41 (8), 1934-1942.
[30] Mali, S., Sakanaka, L.S., Yamashita, F., and Grossman, M.V.E., 2005, Water sorption and mechanical properties of cassava starch films and their relation to plasticizing effect, J. Carbohydr. Polym., 60 (3), 283-289.

[31] Espert, A., Camacho, W., and Karlson, S., 2003, Thermal and thermomechanical properties of biocomposites made from modified recycled cellulose and recycle polypropylene, J. Appl. Polym. Sci., 89, 2353-2360.

[32] Kim, H.S., Yang, H.S., Kim, H.J., Park, H.J., 2004, Thermogravimetric analysis of rice husk flour filled thermoplastic polymer composites, J. Therm. Anal. Calorim., 76 (2), 395-404.

[33] Min A.M., Chuah, T.G., and Chantara, T.R., 2008, Thermal and dynamic mechanical analysis of polyethylene modified with crude palm oil, Mater. Des., 29 (5), 992-999. 